\title{
Acid-catalyzed ring-opening reactions of a cyclopropanated 3-aza-2-oxabicyclo[2.2.1]hept-5-ene with alcohols
}

\author{
Katrina Tait ${ }^{1}$, Alysia Horvath ${ }^{1}$, Nicolas Blanchard ${ }^{2}$ and William Tam ${ }^{* 1}$
}

\author{
Full Research Paper \\ Address: \\ ${ }^{1}$ Guelph-Waterloo Centre for Graduate Work in Chemistry and \\ Biochemistry, Department of Chemistry, University of Guelph, Guelph, \\ Ontario, N1G 2W1, Canada and 2Laboratoire de Chimie Moléculaire, \\ ECPM-CNRS UMR7509, University of Strasbourg, 25 rue Becquerel, \\ 67087 Strasbourg, France \\ Email: \\ William Tam - wtam@uoguelph.ca \\ * Corresponding author \\ Keywords: \\ acid catalysis; alcohol nucleophiles; cyclopropanation; heterobicyclic \\ compounds; ring-opening reactions \\ Beilstein J. Org. Chem. 2017, 13, 2888-2894. \\ doi:10.3762/bjoc. 13.281 \\ Received: 05 November 2017 \\ Accepted: 17 December 2017 \\ Published: 27 December 2017 \\ Associate Editor: M. Rueping \\ (C) 2017 Tait et al.; licensee Beilstein-Institut. \\ License and terms: see end of document.
}

\begin{abstract}
The acid-catalyzed ring-opening reactions of a cyclopropanated 3-aza-2-oxabicylic alkene using alcohol nucleophiles were investigated. Although this acid-catalyzed ring-opening reaction did not cleave the cyclopropane unit as planned, this represent the first examples of ring-openings of cyclopropanated 3-aza-2-oxabicyclo[2.2.1]alkenes that lead to the cleavage of the C-O bond instead of the $\mathrm{N}-\mathrm{O}$ bond. Different acid catalysts were tested and it was found that pyridinium toluenesulfonate in methanol gave the best yields in the ring-opening reactions. The scope of the reaction was successfully expanded to include primary, secondary, and tertiary alcohol nucleophiles. Through X-ray crystallography, the stereochemistry of the product was determined which confirmed an $\mathrm{S}_{\mathrm{N}}$ 2-like mechanism to form the ring-opened product.
\end{abstract}

\section{Introduction}

Heterobicyclic alkenes are useful templates to generate complex cyclic and acyclic systems [1,2]. 3-Aza-2-oxabicyclic alkenes are particularly interesting due to their asymmetric nature and the ability to modify selected components of the molecule to create vastly different products. 3-Aza-2-oxabicyclic alkenes are generally modified in one of four ways (Scheme 1). One of the most interesting manipulations of 3-aza2-oxabicyclic alkenes is the modification of the alkene component. The manipulation of the olefin can lead to a wide variety of products often in a single step, which is synthetically useful to create many highly substituted products with different stereochemical outcomes (Scheme 2). There are many reported examples in the literature of the modification of the alkene component which includes the reduction to form alkane 8 [3], oxidative cleavage of the $\mathrm{C}=\mathrm{C}$ bond to form 9 [4], ring-opening metathesis to form functionalized alkenes $\mathbf{1 0}$ and 11 [4], dihydroxylation to form diol 12 [5], ruthenium-catalyzed [2+2] cycloaddition with unsymmetrical alkynes to form regioisomers $\mathbf{1 3}$ 

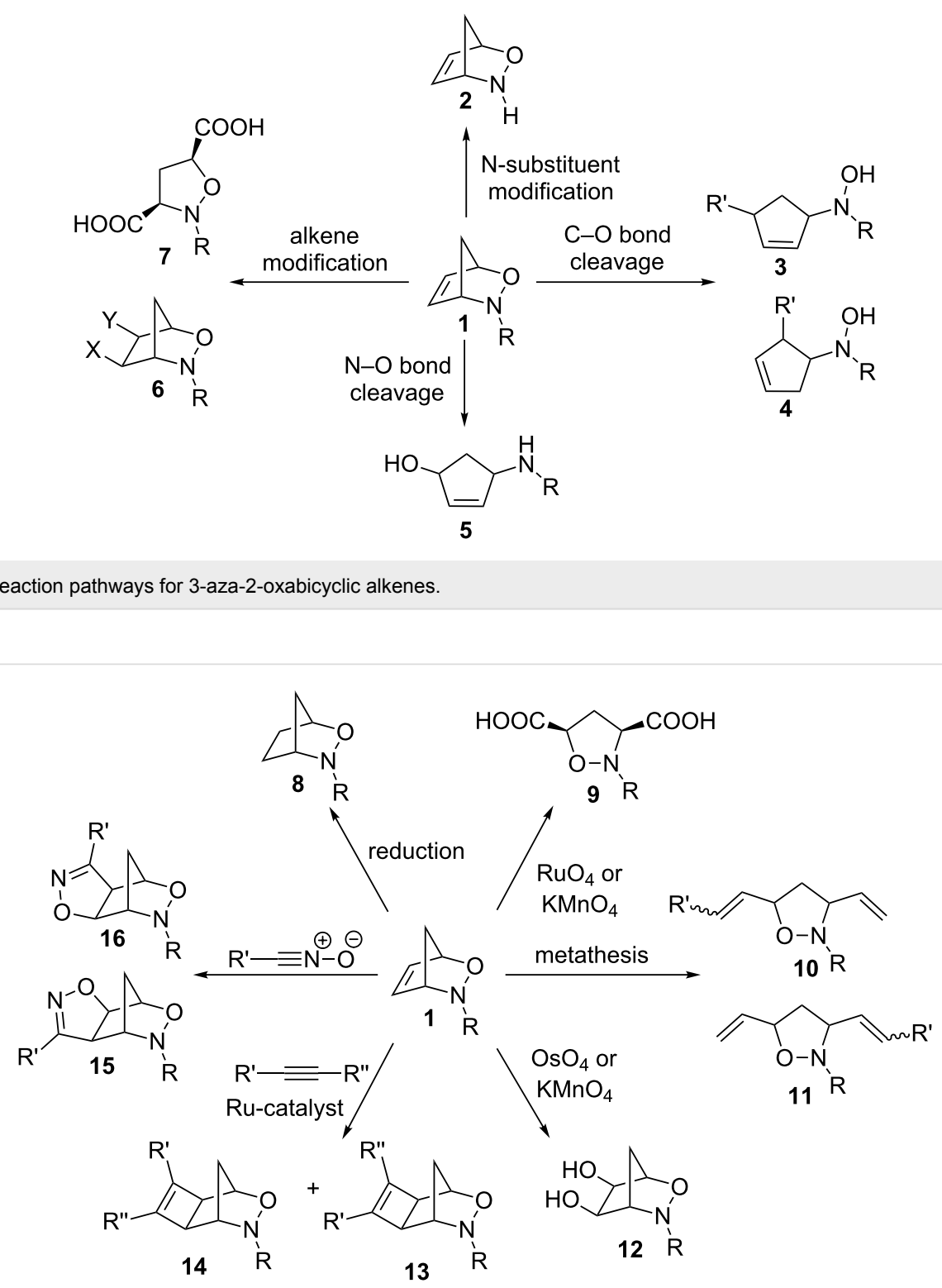

Scheme 2: Various reactions involving modification of the alkene component of 3-aza-2-oxabicyclic alkenes.

and 14 [6], and cycloadditions using nitrile oxides to provide 15 and $16[7]$.

In the literature, there are also many examples of the cleavage of the $\mathrm{C}-\mathrm{O}$ bond of 3-aza-2-oxabicyclic alkenes 1 (Scheme 3). This includes the use of protic acid [8], using metal catalysts such as $\mathrm{Pd}$ [9], $\mathrm{Fe}$ or $\mathrm{Cu}$ [10], In [11], organozinc or Grignard reagents [12], $\mathrm{Rh}[13]$, and $\mathrm{Ru}$ [14] catalysts.

Another interesting modification of the alkene component is cyclopropanation. To date, there are a few reported examples in the literature of the cyclopropanation of 3-aza-2-oxabicyclic alkenes [15-17]. The addition of a cyclopropane unit adds ring- strain to the molecule that could lead to different pathways for ring-opening and further reactivity.

While the reactivity of 3-aza-2-oxabicyclo[2.2.1]hept-5-enes has been extensively studied (Scheme 1 and Scheme 2), there are only two examples in the literature investigating the reactivity of the cyclopropanated derivative (Scheme 4) and in both studies, cleavage of the $\mathrm{N}-\mathrm{O}$ bond (b) was observed. While the Buono group demonstrated the reductive $\mathrm{N}-\mathrm{O}$ bond cleavage to produce compound $\mathbf{2 5}$ as proof-of-principle [16], the Miller group reported the use of the cyclopropanated compound for the synthesis of 2',3'-methano carbocyclic nucleosides via compound 24 (Scheme 5) [17]. Carbocyclic nucleosides are impor- 


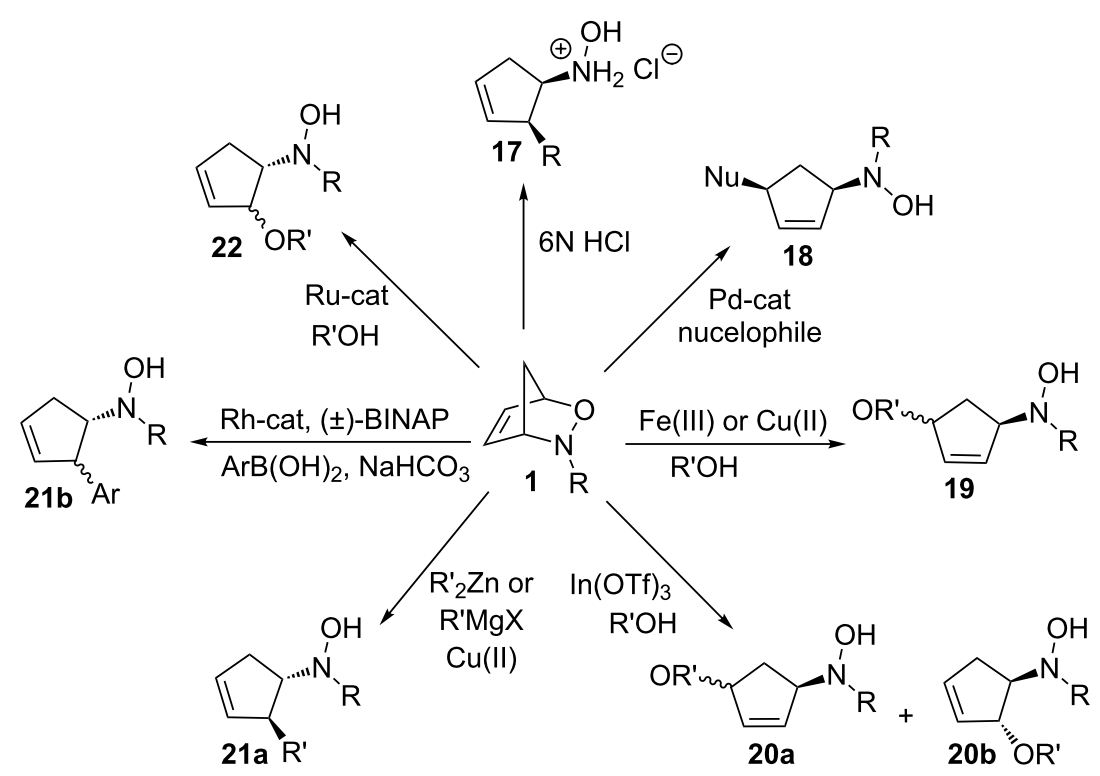

Scheme 3: Various reactions involving cleavage of the C-O bond of 3-aza-2-oxabicyclic alkenes.

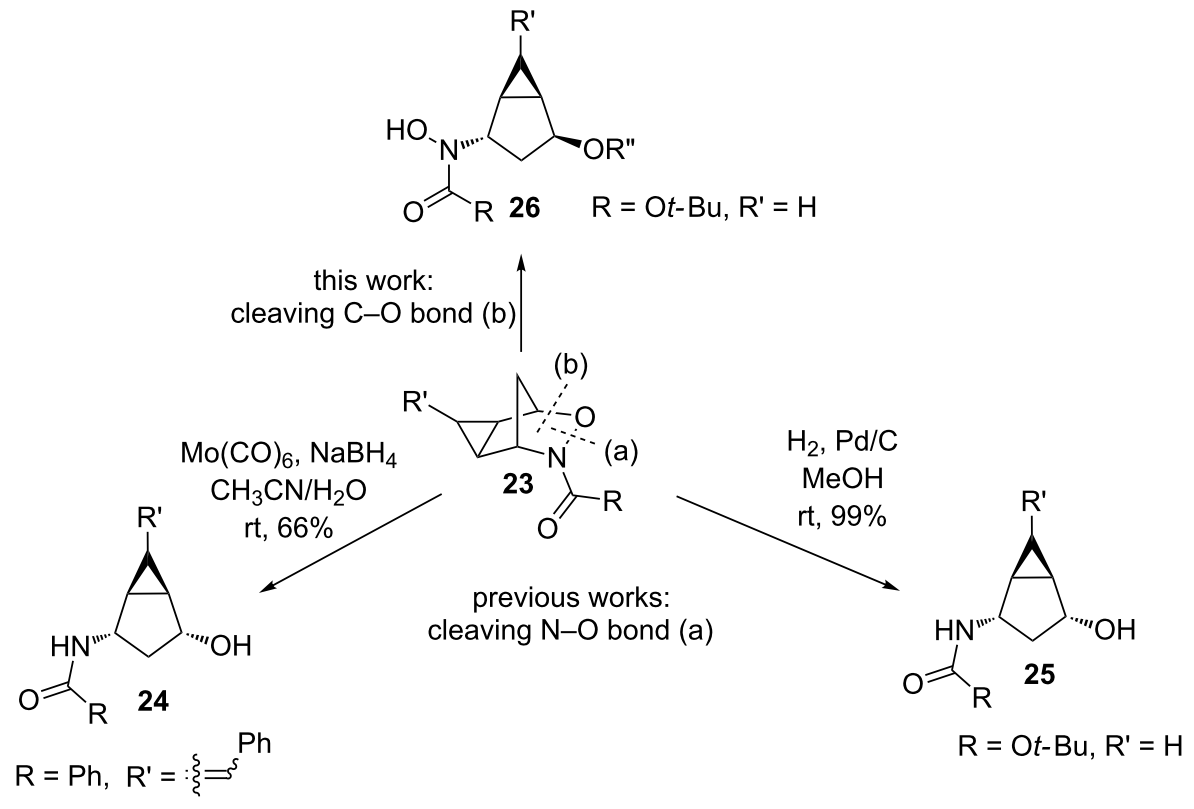

Scheme 4: Ring-opening reactions of cyclopropanated 3-aza-2-oxabicyclic alkenes.

tant synthetic targets because of their use as antiviral and antitumor agents [17]. Replacing the oxygen unit in the parent furanose ring with a methylene unit helps to stabilize the structure against cleavage by nucleoside phosphorylases or hydrolases $[18,19]$. The addition of a cyclopropane unit could provide further rigidity that could better stabilize the compound, thereby enhancing its biological activity. Both of these reported ringopenings of cyclopropanated 3-aza-2-oxabicyclo[2.2.1]alkenes reductively cleave the $\mathrm{N}-\mathrm{O}$ bond (a) (Scheme 4), therefore, no examples cleaving the $\mathrm{C}-\mathrm{O}$ bond have been reported in the literature. In this paper, we aim to explore the use of an acid catalyst with an alcohol nucleophile on the ring-opening of cyclopropanated 3-aza-2-oxabicyclic compound $\mathbf{1 9}$ for the cleavage of the $\mathrm{C}-\mathrm{O}$ bond (b) (Scheme 4). We initially anticipated that the $\mathrm{S}_{\mathrm{N}} 2$ ' type ring-opening would occur which would lead to the formation of ring-opened product 27 (Scheme 5). However, 


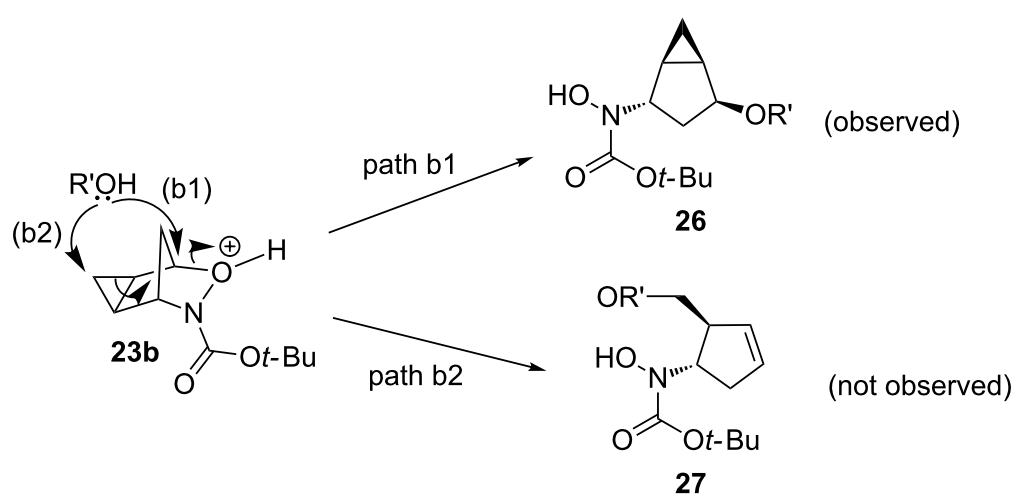

Scheme 5: Different possible ring-opening pathways of cyclopropanated 3-aza-2-oxabicyclic alkenes.

in all cases tested, only the $\mathrm{S}_{\mathrm{N}} 2$ type ring-opened product $\mathbf{2 6}$ was formed.

\section{Results and Discussion}

A variety of different acid catalysts was screened and the results are summarized in Table 1. In the presence of a Lewis acid catalyst (Table 1, entries 1-3), the reaction did not proceed as seen with $\mathrm{FeCl}_{3}$ (Table 1, entry 1) or produced ring-opened product 26 in low yields (Table 1, entries 2 and 3). The effect of inorganic protic acids was then investigated (Table 1, entries 4-6), producing moderate yields of the ring-opened product. The use of fluoroboric acid (Table 1, entry 4) and sulfuric acid (Table 1, entry 5) produced ring-opened product 26 in $45 \%$ and $48 \%$ yield, respectively, while using nitric acid increased the yield to $56 \%$ with trace amount of starting material 23a recovered. Finally, the effect of organic protic acids was investigated (Table 1, entries 7-9) which produced ring-opened product $\mathbf{2 6}$ in low to moderate yields. The use of $p$-toluenesulfonic acid monohydrate produced the ring-opened product at a yield of $38 \%$ (Table 1, entry 7) while using camphorsulfonic acid (CSA) increased the yield to $50 \%$ but took 46 hours to go to completion (Table 1, entry 8 ). The organic acid pyridinium $p$-toluenesulfonate (PPTS) produced the highest yield of ring-opened product with a $61 \%$ yield (Table 1 , entry 9 ) and was chosen to further optimize reaction conditions.

A variety of solvents was screened, including polar protic, aromatic, and polar aprotic solvents (Table 2). When methanol was used as the nucleophile and polar protic solvent, the reaction yielded the ring-opened product in a $61 \%$ yield (Table 2 , entry 1). The use of the aromatic solvent toluene gave a moderate yield of $47 \%$ but took 48 hours to go to completion (Table 2 , entry 2). Polar aprotic solvents DCE, THF, and 1,4-dioxane were investigated, which produced the ring-opened product $\mathbf{2 6}$ in moderate yields (Table 2, entries 3-5). Using DMF decreased the yield significantly to only $6 \%$, with $57 \%$ of starting
Table 1: Effects of acid catalysts on the ring-opening reaction of cyclopropanated 3-aza-2-oxabicyclic alkene 23a with alcohols.

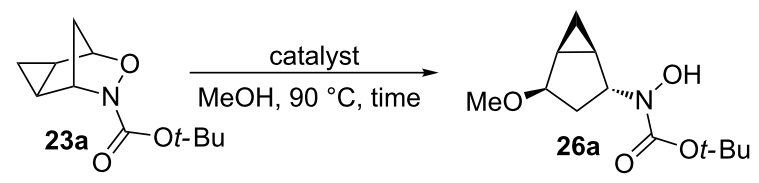

\begin{tabular}{llll}
\hline Entry & Catalyst & Time (h) & Yield (\%) $^{\mathrm{a}}$ \\
\hline 1 & $\mathrm{FeCl}_{3}$ & 22 & 0 \\
2 & $\mathrm{ZrCl}_{4}$ & 24 & 15 \\
3 & $\mathrm{AlCl}_{3}$ & 24 & 32 \\
4 & $\mathrm{HBF}_{4}$ & 24 & 45 \\
5 & $\mathrm{H}_{2} \mathrm{SO}_{4}$ & 24 & 48 \\
6 & $\mathrm{HNO}_{3}$ & 24 & $56^{\mathrm{b}}$ \\
7 & $p-\mathrm{TsOH}_{2} \mathrm{O}$ & 24 & $38^{\mathrm{b}}$ \\
8 & $\mathrm{CSA}$ & 46 & 50 \\
9 & $\mathrm{PPTS}$ & 24 & $61^{\mathrm{b}}$ \\
\hline
\end{tabular}

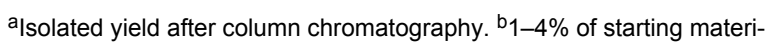
al was recovered.

material 23a recovered after eight days (Table 2, entry 6). The use of the polar aprotic solvent acetonitrile decreased the yield of the reaction to $27 \%$ and took almost five days to complete with $3 \%$ of starting material 23a recovered (Table 2, entry 7). Finally, using DMSO decreased the yield to $32 \%$ with $5 \%$ of starting material recovered after 49 hours (Table 2, entry 8). Since the best result was obtained without the use of a cosolvent, the polar protic nucleophile will be used as both the nucleophile and solvent.

To study the scope of the reaction, the use of different alcohol nucleophiles was tested (Table 3 ). With a primary alcohol, a decrease in reactivity was seen with increasing chain length (Me $<\mathrm{Et}<n$-Bu; Table 3, entries 1-3) while maintaining reasonable yields. When 2-methoxyethanol was used as the 
Table 2: Effect of solvent on the ring-opening reactions of cyclopropanated 3-aza-2-oxabicyclic alkene 23a with alcohols.

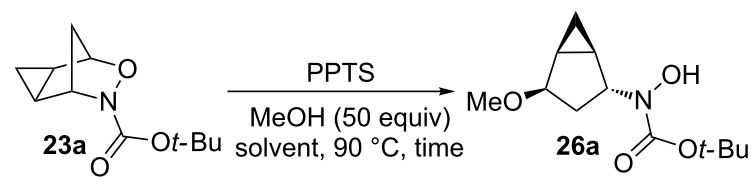

\begin{tabular}{lllll}
\hline Entry & Solvent & Time (h) $\begin{array}{l}\text { Yield } \\
\text { 26a (\%) }\end{array}$ & $\begin{array}{l}\text { Recovered } \\
\text { 23a (\%) }\end{array}$ \\
\hline 1 & MeOH & 24 & 61 & 4 \\
2 & toluene & 48 & 47 & 0 \\
3 & DCE & 24 & 41 & 0 \\
4 & THF & 48 & 39 & 0 \\
5 & 1,4-dioxane & 24 & 39 & 3 \\
6 & DMF & 190 & 6 & 57 \\
7 & CH ${ }_{3} \mathrm{CN}$ & 117 & 27 & 3 \\
8 & DMSO & 49 & 32 & 5 \\
\hline
\end{tabular}

asolated yield after column chromatography.

nucleophile, the yield was decreased to $42 \%$ (Table 3 , entry 4 ) while using isobutyl alcohol produced a similar yield of $41 \%$ (Table 3, entry 5). Using 2-methylbutanol produced a 34\% yield of a 1:1 diastereomeric ratio of product (Table 3, entry 6) and using allyl alcohol produced ring-opened product $\mathbf{2 6} \mathrm{g}$ in a $38 \%$ yield (Table 3, entry 7). The use of secondary alcohols generally resulted in a decrease of yield of the ring-opened product (Table 3, entries 8-11). Isopropanol achieved a moderate yield of $51 \%$ (Table 3, entry 8 ) while using 2-butanol decreased the yield to $28 \%$ of a 1:1 diastereomeric ratio of product (Table 3 , entry 9). The cyclic alcohols cyclohexanol and cyclopentanol (Table 3, entries 10 and 11) produced low amounts of the ringopened alcohol in a $24 \%$ and $26 \%$ yield, respectively. The use of a tertiary alcohol surprisingly resulted in a moderate yield, with tert-butanol producing a $50 \%$ yield of product $\mathbf{2 6}$ (Table 3, entry 12, preparation of compound 261 from 23a and $t$-BuOH with PPTS was already published in reference [20]). When the aromatic alcohol phenol was investigated as a nucleophile, no reaction occurred though no starting material was recovered (Table 3, entry 13). Although in most cases, the starting material was completely consumed, the yields of these ring-opening reactions were only moderate (26-61\%). This may be due to the decomposition or polymerization of the cyclopropanated 3-aza-2-oxabicyclic alkene under the reaction conditions. Through X-ray crystallography [20] and 1D NOESY ${ }^{1} \mathrm{H}$ NMR the stereochemistry of the products was confirmed, with the nucleophile added syn to the cyclopropane ring and anti to the amino alcohol group.

When forming the ring-opening product, there are two possible mechanisms (Scheme 6).
Table 3: Scope of the reaction with different alcohol nucleophiles.

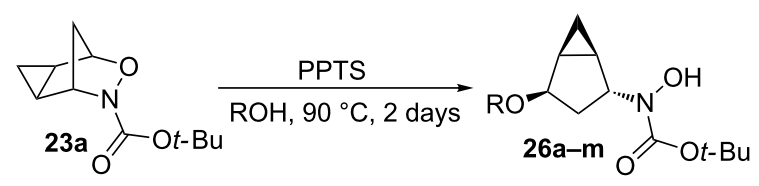

\begin{tabular}{|c|c|c|c|}
\hline Entry & $\mathrm{ROH}$ & Products & Yield $(\%)^{a}$ \\
\hline 1 & $\mathrm{MeOH}$ & $26 a$ & 61 \\
\hline 2 & $\mathrm{EtOH}$ & $26 b$ & 51 \\
\hline 3 & $n$-BuOH & $26 c$ & 36 \\
\hline 4 & $\mathrm{Me}$ & 26d & 42 \\
\hline 5 & $\mathrm{H}$ & $26 e$ & 41 \\
\hline 6 & $\mathrm{OH}$ & $26 f$ & $34^{b}$ \\
\hline 7 & & $26 \mathrm{~g}$ & 38 \\
\hline 8 & iPrOH & $26 h$ & 51 \\
\hline 9 & & $26 i$ & $28^{b}$ \\
\hline 10 & СуОН & 26j & 24 \\
\hline 11 & cyclopentanol & 26k & 26 \\
\hline 12 & $t-\mathrm{BuOH}$ & $26 I$ & 50 \\
\hline 13 & $\mathrm{PhOH}$ & $26 \mathrm{~m}$ & 0 \\
\hline
\end{tabular}

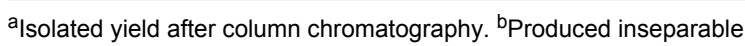
$1: 1$ diastereomeric products.

If the oxygen atom is first protonated followed by cleavage of the $\mathrm{C}-\mathrm{O}$ bond as seen in path $\mathrm{A}$, the free carbocation $\mathbf{2 8}$ would form in an $\mathrm{S}_{\mathrm{N}}$ 1-like manner. The nucleophile could therefore attack from either the top or the bottom, forming products $\mathbf{2 6 a}$ and 29. Alternatively, in path $B$ the oxygen atom could be protonated and undergo an $\mathrm{S}_{\mathrm{N}}$ 2-like mechanism with the nucleophile attacking from the open top face seen in $\mathbf{3 0}$, forming sole product 26a. If a free carbocation was formed as shown in path A, both stereoisomers 26a and 29 should have been observed, which was not evident. Also, if a free carbocation was formed the product likely would have undergone rearrangement of the cyclopropyl cation to ring-open the cyclopropane ring and form either a five or six-membered product, however, the cyclopropane is proved to be intact. Therefore, since only one single product 26a was observed, it is confirmed the product is formed through an $\mathrm{S}_{\mathrm{N}}$ 2-like pathway seen in path B.

\section{Conclusion}

In conclusion, we have demonstrated the first examples of acidcatalyzed nucleophilic ring-opening reactions of a cyclopropanated 3-aza-2-oxabicyclic alkene with alcohols. Although 


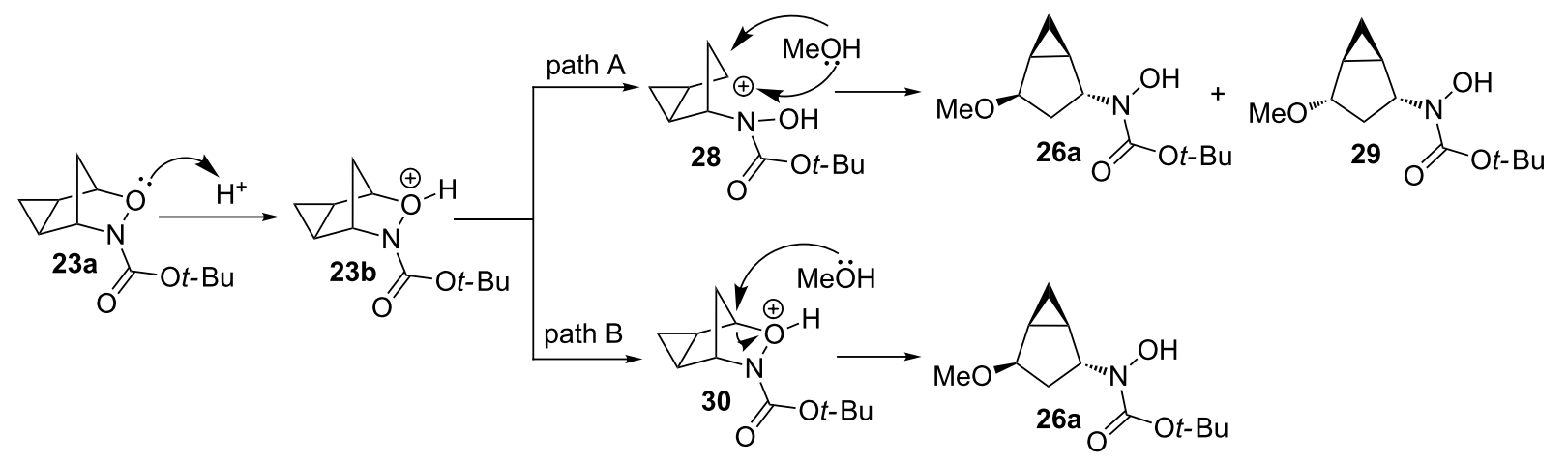

Scheme 6: Possible mechanisms for the nucleophilic ring-opening of cyclopropanated 3-aza-2-oxabicyclic alkene 19.

this acid-catalyzed ring-opening reaction did not cleave the cyclopropane unit as planned, this represent the first examples of ring-openings of cyclopropanated 3-aza-2-oxabicyclo[2.2.1]alkenes that lead to the cleavage of the $\mathrm{C}-\mathrm{O}$ bond instead of the $\mathrm{N}-\mathrm{O}$ bond. Different acid catalysts were tested and it was found that pyridinium toluenesulfonate in methanol gave the best yields in the ring-opening reactions. The scope of the reaction was successfully expanded to include primary, secondary, and tertiary alcohol nucleophiles. Through X-ray crystallography, the stereochemistry of the product was determined which confirmed an $\mathrm{S}_{\mathrm{N}}$ 2-like mechanism to form the ringopened product. Further investigation of the ring-opening reactions of cyclopropanated 3-aza-2-oxabicyclo[2.2.1]alkenes using other metal catalysts, such as those listed in Scheme 3, is ongoing in our laboratory.

\section{Supporting Information}

Experimental procedures and copies of ${ }^{1} \mathrm{H}$ and ${ }^{13} \mathrm{C}$ NMR spectra for compounds are provided in the Supporting Information.

\section{Supporting Information File 1}

Experimental.

[http://www.beilstein-journals.org/bjoc/content/

supplementary/1860-5397-13-281-S1.pdf]

\section{Supporting Information File 2}

NMR spectra.

[http://www.beilstein-journals.org/bjoc/content/ supplementary/1860-5397-13-281-S2.pdf]

\section{Acknowledgements}

This work was supported by the Natural Sciences and Engineering Research Council of Canada (NSERC).

\section{ORCID ${ }^{\circledR}$ iDs}

Nicolas Blanchard - https://orcid.org/0000-0002-3097-0548

\section{References}

1. Bournaud, C.; Chung, F.; Pérez Luna, A.; Pasco, M.; Errasti, G.; Lecourt, T.; Micouin, L. Synthesis 2009, 869-887. doi:10.1055/s-0028-1087980

2. Tam, W.; Cockburn, N. Synlett 2010, 1170-1189. doi:10.1055/s-0029-1219780

3. Just, G.; Cutrone, L. Can. J. Chem. 1976, 54, 867-870. doi:10.1139/v76-125

4. Ellis, J. M.; King, S. B. Tetrahedron Lett. 2002, 43, 5833-5835.

5. Ranganathan, S.; George, K. S. Tetrahedron 1997, 53, 3347-3362. doi:10.1016/S0040-4020(97)00057-4

6. Durham, R.; Mandel, J.; Blanchard, N.; Tam, W. Can. J. Chem. 2011, 89, 1494-1505. doi:10.1139/V11-135

7. Bodnar, B. S.; Miller, M. J. J. Org. Chem. 2007, 72, 3929-3932.

8. Muxworthy, J. P.; Wilkinson, J. A.; Procter, G. Tetrahedron Lett. 1995, 36, 7535-7538. doi:10.1016/0040-4039(95)01525-6

9. Miller, A.; Procter, G. Tetrahedron Lett. 1990, 31, 1043-1046.

10. Surman, M. D.; Miller, M. J. J. Org. Chem. 2001, 66, 2466-2469. doi:10.1021/jo010094a

11. Yang, B.; Miller, M. J. J. Tetrahedron Lett. 2009, 74, 7990-7993. doi:10.1016/j.tetlet.2009.12.006

12. Surman, M. D.; Mulvihill, M. J.; Miller, M. J. J. Org. Chem. 2002, 67, 4115-4121. doi:10.1351/pac200678020463

13. Machin, B. P.; Ballantine, M.; Mandel, J.; Blanchard, N.; Tam, W. J. Org. Chem. 2009, 74, 7261-7266. doi:10.1021/jo901248w

14. Machin, B. P.; Howell, J. H.; Mandel, J.; Blanchard, N.; Tam, W. Org. Lett. 2009, 11, 2077-2080. doi:10.1021/ol900454q

15. Carlson, E.; Duret, G.; Blanchard, N.; Tam, W. Synth. Commun. 2015, $46,55-62$.

16. Bigeault, J.; Giordano, L.; De Riggi, I.; Gimbert, Y.; Buono, G. Org. Lett. 2007, 9, 3567-3570. doi:10.1021/ol071386m

17. Ji, C.; Miller, M. J. Tetrahedron Lett. 2010, 51, 3789-3791. doi:10.1016/j.tetlet.2010.05.062

18. Crimmins, M. T. Tetrahedron 1998, 54, 9229-9272. doi:10.1016/S0040-4020(98)00320-2

19. Altona, C.; Sundaralingam, M. J. Am. Chem. Soc. 1972, 94 , 8205-8212. doi:10.1021/ja00778a043 
20. Lough, A. J.; Tait, K.; Horvath, A.; Tam, W. IUCrData 2017, 2, x171419. doi:10.1107/S2414314617014195

\section{License and Terms}

This is an Open Access article under the terms of the Creative Commons Attribution License

(http://creativecommons.org/licenses/by/4.0), which permits unrestricted use, distribution, and reproduction in any medium, provided the original work is properly cited.

The license is subject to the Beilstein Journal of Organic Chemistry terms and conditions:

(http://www.beilstein-journals.org/bjoc)

The definitive version of this article is the electronic one which can be found at:

doi:10.3762/bjoc.13.281 